\title{
Lack of association between HFE gene mutations and hepatocellular carcinoma in patients with cirrhosis
}

\author{
V Boige, L Castéra, N de Roux, N Ganne-Carrié, B Ducot, G Pelletier, M Beaugrand, \\ C Buffet
}

See end of article for authors' affiliations

Correspondence to:

Dr V Boige, Department of

Medicine, Institut Gustave

Roussy, 39 rue Camille

Desmoulins 94805

Villejuif, France;

boige@igr.fr

Accepted for publication

28 January 2003

\begin{abstract}
Background: Liver cirrhosis may lead to hepatocellular carcinoma $(\mathrm{HCC})$, regardless of its cause. Genetic and/or environmental factors may modulate the risk of HCC. Mutations in the HFE gene are responsible for genetic haemochromatosis, a condition known to be associated with liver cirrhosis, $\mathrm{HCC}$, or both. It has recently been suggested that the C282Y HFE gene mutation may be more frequent in patients with HCC that have developed in the non-cirrhotic liver than in the general population. Whether or not HFE gene mutations are associated with an increased risk of $\mathrm{HCC}$ in patients with cirrhosis is unknown.

Aim: To assess the prevalence of HFE gene mutations in cirrhotic patients with and without HCC.

Patients and methods: A total of 133 consecutive cirrhotic patients with HCC were prospectively studied for the presence of $\mathrm{C} 282 \mathrm{Y}$ and H63D mutations. The control group consisted of 100 cirrhotic patients without HCC. We used restriction enzyme digestion of polymerase chain reaction amplified genomic DNA for determination of HFE genotypes. Iron loading was assessed on non- tumoral liver biopsy samples from 89 patients with HCC and 73 patients without HCC.

Results: The prevalence of $\mathrm{C} 282 \mathrm{Y}$ heterozygotes was similar in patients with and without $\mathrm{HCC} 15 \% \mathrm{v}$ $4 \%$, respectively; $p=0.65$ ) and did not differ from that expected in the general population. None of the $\mathrm{HCC}$ patients was found to be homozygous for $\mathrm{C} 282 \mathrm{Y}$ or H63D, nor compound heterozygous. The prevalence of H63D heterozygotes was similar in patients with and without $\mathrm{HCC} 131 \% v 38 \%$, respectively; $p=0.25)$. No relation was detected between HFE genotypes and hepatic iron loading in patients with or without $\mathrm{HCC}$.

Conclusion: C282Y and H63D mutations do not appear to be associated with an increased risk of $\mathrm{HCC}$ in patients with cirrhosis.
\end{abstract}

iver cirrhosis is a major aetiological factor for the occurrence of hepatocellular carcinoma (HCC). The annual incidence of HCC in patients with liver cirrhosis is $3-5 \%{ }^{1-3}$ However not all patients with cirrhosis develop HCC. Thus identification of high risk patients for HCC is important to increase the rate of early detection by intensive screening programmes and subsequently to try to improve the impact of radical curative therapies on survival. Several risk factors for developing HCC have been identified in Western patients with cirrhosis, including male sex, age above 50 years, persistently raised serum $\alpha$ fetoprotein levels, severity of cirrhosis (large oesophageal varices and abnormal prothrombin time), and anti- hepatitis $\mathrm{C}$ antibodies.

Patients with genetic haemochromatosis (GH) are also at high risk for developing HCC, even in the absence of cirrhosis or despite complete depletion of tissue iron..$^{4-7}$ Two missense mutations of the HFE gene have been associated with 60-90\% of all cases of GH. ${ }^{8}$ Eighty two to $100 \%$ of patients with GH are homozygous for the first and major mutation termed C282Y and $4 \%$ are compound heterozygotes for the $\mathrm{C} 282 \mathrm{Y}$ mutation and the second and minor mutation termed H63D. ${ }^{8}$

An increased prevalence of the HFE C282Y mutation has recently been reported in patients with HCC that developed in the non-cirrhotic liver with mild iron overload, ${ }^{9-11}$ suggesting a possible involvement of the heterozygous state for the C282Y mutation in hepatocarcinogenesis. Such a putative role for H63D remains elusive ${ }^{11}$ as this mutation in the absence of $\mathrm{C} 282 \mathrm{Y}$ has not been associated with significant iron overload or HCC thus far. ${ }^{12}$ This prompted us to prospectively assess the prevalence of $\mathrm{C} 282 \mathrm{Y}$ and $\mathrm{H} 63 \mathrm{D}$ mutations in cirrhotic patients with or without HCC.

\section{PATIENTS AND METHODS Patients}

Between May 1997 and November 1999, 133 consecutive patients with cirrhosis and HCC were prospectively screened for HFE gene mutations after informed consent had been obtained. During the same period, blood samples from a control group of 100 patients with cirrhosis without HCC were also collected. Patients with suspicion of $\mathrm{GH}$, based on usual criteria (history of liver disease or iron overload in first degree relatives, typical manifestations of $\mathrm{GH}$ such as arthralgias, skin hyperpigmentation, and overt diabetes mellitus) $)^{13}$ were excluded. The diagnosis of HCC was based either on histology after fine needle guided biopsy or on the presence of a focal liver lesion on ultrasonography or computed tomography scan with elevated serum $\alpha$ fetoprotein levels above $250 \mathrm{UI} / \mathrm{ml}$. The threshold value of $250 \mathrm{UI} / \mathrm{ml}$ was chosen as a diagnostic criterion according to that used in our previous study. ${ }^{14}$ Liver cirrhosis was either histologically proved or diagnosed on concordant clinical, biological, and morphological criteria.

\section{Methods}

Genomic DNA was extracted from peripheral blood leucocytes by standard procedures. DNA fragments were amplified by polymerase chain reaction (PCR) using primers and reaction conditions as described previously. ${ }^{8}$ The PCR products were digested with the restriction enzymes RsaI and DpnII to detect the $\mathrm{C} 282 \mathrm{Y}$ and $\mathrm{H} 63 \mathrm{D}$ mutations, respectively.

Abbreviations: $\mathrm{GH}$, genetic haemochromatosis; HCC, hepatocellular carcinoma; PCR, polymerase chain reaction. 
Table 1 Clinical characteristics and HFE genotype distibution in 133 cirrhotic patients with HCC and 100 cirrhotic patients without HCC.

\begin{tabular}{|c|c|c|c|}
\hline & $\begin{array}{l}\mathrm{HCC} \\
(n=133)\end{array}$ & $\begin{array}{l}\text { No HCC } \\
(n=100)\end{array}$ & $\mathrm{p}$ Value \\
\hline Age (y) (mean (SD)) & 64 (10) & $58(13)$ & 0.0003 \\
\hline Sex (male/female) & $113 / 20$ & $65 / 35$ & 0.0001 \\
\hline Aetiology of cirrhosis (\%) & & & NS \\
\hline Alcohol & $76(57)$ & $57(57)$ & \\
\hline $\mathrm{HCV}$ & $30(22)$ & $26(26)$ & \\
\hline HBV & $9(7)$ & $4(4)$ & \\
\hline Mixed* & 17 (13) & $9(9)$ & \\
\hline Othert & $1(1)$ & $4(4)$ & \\
\hline HFE genotype (\%) & & & NS \\
\hline $\mathrm{C} 282 \mathrm{Y} / \mathrm{C} 282 \mathrm{Y}$ & $0(0)$ & 1 (1) & \\
\hline C282Y/H63D & $0(0)$ & $2(2)$ & \\
\hline $\mathrm{H} 63 \mathrm{D} / \mathrm{H} 63 \mathrm{D}$ & $0(0)$ & 1 (1) & \\
\hline C282Y/WT & 7 (5) & $4(4)$ & \\
\hline H63D/WT‡ & $41(31)$ & $38(38)$ & \\
\hline WT/WT $\ddagger$ & 85 (64) & $54(54)$ & \\
\hline
\end{tabular}

$\mathrm{HCC}$, hepatocellular carcinoma; $\mathrm{HCV}$, hepatitis $\mathrm{C}$ virus; $\mathrm{HBV}$, hepatitis $B$ virus.

*Alcohol and $\mathrm{HCV} /$ alcohol and HBV.

† Primary biliary cirrhosis $(n=3)$, cryptogenetic cirrhosis $(n=2)$. $\neq$ WT, wild type.

Liver iron loading was assessed in a semiquantitative fashion using Perls' Prussian blue staining on 162 available non-tumoral liver biopsy samples (89 with and 73 without HCC) as follows: 0 , no staining; 1 , minimal to moderate iron overload ( $<50 \%$ stained hepatocytes); and 2, massive iron overload ( $>50 \%$ stained hepatocytes).

\section{Statistics}

The two groups of patients (with or without HCC) were compared for sex, aetiology of cirrhosis, liver iron loading, and HFE genotype distribution, using the $\chi^{2}$ test or Fisher's exact test when appropriate. They were compared for age using analysis of variance. HFE gene mutations and predictive factors of HCC (age and sex) were subsequently included in a logistic regression analysis. A p value $<0.05$ was considered significant.

\section{RESULTS}

Patient characteristics and the distribution of HFE genotypes, according to the presence or the absence of HCC, are given in table 1. Except for age and sex, the two groups were comparable, particularly for aetiology of cirrhosis.

The $\mathrm{C} 282 \mathrm{Y}$ mutation was present on $2.6 \%$ of chromosomes from patients with HCC compared with $3.0 \%$ of chromosomes from patients without HCC $(p=0.44)$. The prevalence of $\mathrm{C} 282 \mathrm{Y}$
Table 3 Liver iron loading in 162 cirrhotic patients with and without HFE gene mutations

\begin{tabular}{|c|c|c|}
\hline & $\begin{array}{l}\text { C282Y and/or } \\
\text { H63D* }\end{array}$ & No mutation $†$ \\
\hline Grade 0 & 37 & 64 \\
\hline Grade 1 & 18 & 18 \\
\hline Grade 2 & 14 & 11 \\
\hline $\mathrm{p}$ Value & 0.13 & \\
\hline \multicolumn{3}{|c|}{$\begin{array}{l}{ }^{*} \mathrm{C} 282 \mathrm{Y} \text { heterozygotes, } \mathrm{H} 63 \mathrm{D} \text { heterozygotes, } \\
\text { and compound heterozygotes were considered } \\
\text { together. } \\
\text { †No mutation=wild-type/wild-type. }\end{array}$} \\
\hline
\end{tabular}

heterozygotes was similar in patients with and without HCC $(5 \% \vee 4 \%$, respectively; $\mathrm{p}=0.65)$ and did not differ from that expected in the normal French population $(3.6 \%) .^{15}$

The frequency of the H63D mutation was $15.4 \%$ of chromosomes from patients with HCC compared with $20.5 \%$ in those without $(p=0.12)$. The prevalence of H63D heterozygotes was similar in patients with and without HCC $(31 \% \vee 38 \%$, respectively; $p=0.25$ ) and slightly higher than that of $23.7 \%$ expected in the normal French population..$^{15}$ None of the HCC patients was found to be a C282Y homozygote, H63D homozygote, or compound heterozygote.

Overall, no significant difference for the prevalence of C282Y and H63D mutations was observed between the two groups, even after adjustment for age and sex. When patients were studied according to aetiology of cirrhosis, no significant difference for the prevalence of the $\mathrm{C} 282 \mathrm{Y}$ and $\mathrm{H} 63 \mathrm{D}$ mutations was observed between the two groups of patients (table 2). Similarly, when considering patients with and without HCC together, the distribution of HFE genotypes did not differ according to the aetiology of cirrhosis.

Patients with available non-tumoral liver tissue samples did not differ from those without for most characteristics (age, sex, aetiology of cirrhosis, HFE genotypes). Hepatic iron loading did not differ between patients with and without HCC $(\mathrm{p}=0.8)$. Finally, no significant correlation between HFE genotype and hepatic iron loading was observed in patients with or without HCC (table 3).

\section{DISCUSSION}

The main result of this large prospective multicentre study was that the prevalence of C282Y and H63D HFE gene mutations did not differ between cirrhotic patients with and without HCC.

Several studies have previously suggested that the prevalence of HFE gene mutations was higher in cirrhotic patients

Table 2 Distribution of HFE genotypes according to the aetiology of cirrhosis and the presence of $\mathrm{HCC}$ in 233 cirrhotic patients ( 133 with HCC, 100 without HCC)

\begin{tabular}{|c|c|c|c|c|c|c|}
\hline & \multicolumn{2}{|c|}{ Alcoholic $(n=133)$} & \multicolumn{2}{|c|}{ Viral $(n=69)$} & \multicolumn{2}{|c|}{ Mixed and other $(n=31)$} \\
\hline & $\begin{array}{l}\mathrm{HCC}- \\
(n=57)\end{array}$ & $\begin{array}{l}\mathrm{HCC}+ \\
(n=76)\end{array}$ & $\begin{array}{l}\mathrm{HCC}_{-} \\
(n=30)\end{array}$ & $\begin{array}{l}\mathrm{HCC}+ \\
(n=39)\end{array}$ & $\begin{array}{l}\mathrm{HCC}_{-} \\
(n=13)\end{array}$ & $\begin{array}{l}\mathrm{HCC}+ \\
(n=18)\end{array}$ \\
\hline $\mathrm{C} 282 \mathrm{Y} / \mathrm{C} 282 \mathrm{Y}$ & 1 & 0 & 0 & 0 & 0 & 0 \\
\hline $\mathrm{C} 282 \mathrm{Y} / \mathrm{H} 63 \mathrm{D}$ & 1 & 0 & 0 & 0 & 1 & 0 \\
\hline H63D/H63D & 0 & 0 & 1 & 0 & 0 & 0 \\
\hline C282Y/WT* & 0 & 5 & 2 & 1 & 2 & 1 \\
\hline H63D/WT* & 23 & 24 & 11 & 13 & 4 & 4 \\
\hline WT/WT* & 32 & 47 & 16 & 25 & 6 & 13 \\
\hline $\mathrm{p}$ Valuet & \multicolumn{2}{|c|}{0.10} & \multicolumn{2}{|c|}{0.52} & \multicolumn{2}{|c|}{0.36} \\
\hline
\end{tabular}

HCC-, without hepatocellular carcinoma; $\mathrm{HCC}+$, with hepatocellular carcinoma

*WT, wild type

tThe $p$ value was obtained by comparing the distribution of $\mathrm{HCC}$ genotype according to either the presence or absence of HCC in alcoholic, viral, and mixed/other cirrhosis. 
with HCC compared with those without HCC. ${ }^{16-19}$ Willis and colleagues ${ }^{16}$ reported a $7 \%$ prevalence of the $\mathrm{C} 282 \mathrm{Y}$ homozygous mutation in patients with HCC, significantly higher than that of $0.7 \%$ expected in the normal population. It must be stressed however that this study was performed retrospectively on a limited number of patients $(n=28)$ by extracting DNA from archived tissue samples. In a population of 181 patients with alcoholic cirrhosis, Lauret and colleagues ${ }^{17}$ found that the prevalence of the C282Y heterozygous mutation was significantly higher in 43 patients with HCC than in 136 without HCC $(20.9 \%$ and $4.4 \%$, respectively; $p=0.002)$. This result was not observed in another group of 98 patients with viral cirrhosis of whom 34 had HCC. In the present study, the prevalence of the $\mathrm{C} 282 \mathrm{Y}$ heterozygous mutation in patients with HCC was lower $(5 \%)$ and did not differ between patients with alcoholic and viral cirrhosis $(6.6 \%$ and $2.6 \%$, respectively). Aldersley and colleagues ${ }^{18}$ found a $6.3 \%$ prevalence of the $\mathrm{C} 282 \mathrm{Y}$ homozygous mutation in 32 patients with HCC compared with $0 \%$ in a group of 82 chronic cholestatic liver disease controls, and a $25 \%$ prevalence of the C282Y heterozygous mutation in HCC patients compared with $5 \%$ in controls. However, these results are difficult to interpret as the underlying liver disease in the HCC group was not specified. In a study including 65 patients with alcoholic or viral cirrhosis and HCC, Cauza and colleagues ${ }^{19}$ found a $10.8 \%$ prevalence of $\mathrm{C} 282 \mathrm{Y}$ heterozygotes. This prevalence was considered to be higher than that expected in the normal population. ${ }^{20}$

Overall, the finding of a high prevalence of HFE gene mutations in HCC patients in these four studies ${ }^{16-19}$ should be interpreted with caution because of their methodological flaws, including retrospective nature, lack of a cirrhotic control group, and limited number of patients studied. In the present study, HFE gene mutations were assessed prospectively in a large cohort of well characterised cirrhotic patients. Although we did not screen HFE genotypes in a healthy control group, the prevalence of heterozygotes for the $\mathrm{C} 282 \mathrm{Y}$ mutation observed in our cirrhotic patients with and without HCC $(5 \%$ and $4 \%$, respectively) was similar to that $(3.6 \%)$ expected in the normal French population. ${ }^{15}$ Furthermore, the prevalence of heterozygotes for the H63D mutation observed in our cirrhotic patients with and without HCC $(31 \%$ and 38\%, respectively) was consistent with that reported by Lauret and colleagues ${ }^{17}$ in patients with alcoholic or viral cirrhosis and in healthy controls $(31.3 \%, 29.6 \%$, and $37.7 \%$, respectively).

Although we did not measure hepatic iron concentration, we were able to assess liver iron loading in a semiquantitative fashion using Perls' Prussian blue staining on 162 available non-tumoral liver biopsy samples ( 89 with and 73 without HCC). We did not find any correlation between liver iron loading and HFE genotype. The impact of C282Y and H63D heterozygosity on iron overload remains debated. Determination of the phenotypic expression of HFE mutations in a large French population showed that hepatic iron overload in nonC282Y homozygous patients was mild to moderate and strikingly lower than in $\mathrm{C} 282 \mathrm{Y}$ homozygous patients. ${ }^{21}$ Similarly, HFE gene mutations do not seem to play a major role in hepatic iron overload associated with liver diseases other than $\mathrm{GH}$. Indeed, heterozygosity for HFE gene mutations seems to contribute to, but does not fully explain, hepatic iron accumulation in patients with chronic hepatitis C. ${ }^{2022}$ Also, it does not seem to influence liver iron content or fibrosis in alcoholic patients. ${ }^{24}$ Conversely, we cannot exclude the fact that absence of correlation between liver iron loading and HFE genotype may be due to lack of reliability of hepatic iron content determinations in cirrhotic patients. Indeed, a considerable intrahepatic variability in iron concentration and frequent overlap in these values between $\mathrm{GH}$ and end stage liver cirrhosis have been reported. ${ }^{25} 26$

Liver iron overload has been reported in non-tumoral liver of most patients with HCC developed in non-cirrhotic liver, suggesting that it may act as a co-carcinogenic agent. ${ }^{1127}$
However, liver iron loading did not differ between cirrhotic patients with and without HCC in the present study, a finding in keeping with our previous work where we did not find a significant relation between hepatic iron content and the occurrence of HCC in patients with alcoholic or hepatitis C virus related cirrhosis. ${ }^{28}$ Thus the role of liver iron overload in HCC development in cirrhotic patients without GH remains to be elucidated.

In conclusion, the similar prevalence of $\mathrm{C} 282 \mathrm{Y}$ and $\mathrm{H} 63 \mathrm{D}$ mutations in cirrhotic patients with or without HCC suggests a lack of association between HFE gene mutations and HCC in patients with cirrhosis. These mutations do not appear to be associated with an increased risk of HCC in patients with cirrhosis without iron overload.

\section{Authors' affiliations}

V Boige, L Castéra, G Pelletier, C Buffet, Department of

Hepatogastroenterology, Hôpital Bicêtre, Université Paris-Sud, 94275 Le Kremlin-Bicêtre, France

N de Roux, Department of Hormonology and Molecular Biology, Hôpital Bicêtre, Université Paris-Sud, 94275 Le Kremlin-Bicêtre, France

N Ganne-Carrié, M Beaugrand, Department of

Hepatogastroenterology, Hôpital Jean Verdier, Université Paris-Nord 93010 Bondy, France

B Ducot, Department of Epidemiology INSERM U292, Hôpital Bicêtre,

Université Paris-Sud, 94275 Le Kremlin-Bicêtre, France

\section{REFERENCES}

1 Ganne-Carrie N, Chastang C, Chapel F, et al. Predictive score of hepatocellular carcinoma and additional value of liver large cell dysplasia in Western patients with cirrhosis. Hepatology 1996;23:1 $112-8$

2 Cottone $M$, Turri $M$, Caltagirone $M$, et al. Screening for hepatocellular carcinoma in patients with Child's A cirrhosis: an 8-year prospective study by ultrasound and alphafoetoprotein. J Hepatol 1994;21:102934.

3 Colombo M, de Franchis R, Del Ninno E, et al. Hepatocellular carcinoma in Italian patients with cirrhosis. N Engl J Med 1991;325:675-80

$4 \mathrm{Kew}$ MD. Pathogenesis of hepatocellular carcinoma in hereditary hemochromatosis: occurrence in non-cirrhotic patients. Hepatology 1990;11:1086-7.

5 Britto MR, Thomas LA, Balaratnam N, et al. Hepatocellular carcinoma in non- cirrhotic liver in genetic haemochromatosis. Scand J Gastroenterol 2000;35:889-93

6 Bradbear R, Bain C, Siskind V, et al. Cohort study of internal malignancy in genetic hemochromatosis and other chronic non-alcoholic liver disease. I Natl Cancer Inst 1985;75:81-4.

7 Fargion S, Mandelli C, Piperno A, et al. Survival and prognosis factors in 212 italian patients with genetic hemochromatosis. Hepatology 1992; 15:655-9.

8 Feder JN, Gnirke A, Thomas W, et al. A novel MHC class I-like gene is mutated in patients with hereditary haemochromatosis. Nat Genet 1996;13:399-408

9 Bralet MP, Degott C, Belghiti J, et al. Prevalence of the haemochromatosis gene mutation in non-cirrhotic liver with hepatocellular carcinoma. J Hepatol 1998;28:740-1.

10 Blanc JF, De Ledinghen V, Trimoulet $\mathrm{P}$, et al. Premalignant lesions and hepatocellular carcinoma in a non-cirrhotic alcoholic patient with iron overload and normal transferrin saturation. J Hepatol 1999:30:325-9.

11 Blanc JF, De Ledinghen V, Bernard PH, et al. Increased incidence of HFE C282Y mutations in patients with iron overload and hepatocellular carcinoma developed in non- cirrhotic liver. J Hepatol 2000;32:805-1 1.

12 Gochee PA, Powell LW, Cullen DJ, et al. A population-based study of the biochemical expression of the H63D hemochromatosis mutation. Gastroenterology 2002;122:646-51.

13 Powell L, Summers K, Board P, et al. Expression of hemochromatosis in homozygous subjects. Implications for early diagnosis and prevention. Gastroenterology 1990;98:1625-32.

14 Groupe d'Etude et de Traitement du Carcinome Hepatocellulaire. A comparison of lipiodol chemoembolization and conservative treatmen for unresectable hepatocellular carcinoma. N Engl J Med 1995:332:1256-61.

15 Jouanolle AM, Gandon G, Jezequel P, et al. Haemochromatosis and HLA-H. Nat Genet 1996;14:251-2.

16 Willis G, Wimperis JZ, Lonsdale R, et al. Haemochromatosis gene mutation in hepatocellular cancer. Lancet 1997;350:565-6.

17 Lauret E, Rodriguez M, Gonzalez S, et al. HFE gene mutations in alcoholic and virus- related cirrhotic patients with hepatocellular carcinoma. Am J Gastroenterol 2002:9:1016-21.

18 Aldersley MA, Komolmit P, Hamlin PJ, et al. Increased prevalence of the hemochromatosis gene mutations in patients with hepatocellular carcinoma. Gastroenterology 1999:116:A1 182. 
19 Cauza E, Ulrich-Pur H, Peck-Radosavjevic M, et al. HFE mutations in patients with hepatocellular carcinoma. Gastroenterology 1999:116:A1 195.

20 Kazemi-Shiraki L, Datz C, Maier-Dobersberger T, et al. The relation of iron status and hemochromatosis gene mutations in patients with chronic hepatitis C. Gastroenterology 1999;1 16:127-34.

21 Moirand $\mathbf{R}$, Jouanolle AM, Brissot $P$, et al. Phenotypic expression of HFE mutations: a French study of 1110 unrelated iron-overloaded patients and relatives. Gastroenterology 1999:116:372-7.

22 Piperno A, Vergani A, Malosio I, et al. Hepatic iron overload in patients with chronic viral hepatitis: role of HFE gene mutations. Hepatology 1998;28: $1105-9$

23 Thoburn D, Curry G, Spooner R, et al. The role of iron and haemochromatosis gene mutations in the progression of liver disease in chronic hepatitis C. Gut 2002:50:248-52.
24 Grove J, Daly AK, Burt AD, et al. Heterozygotes for HFE mutations have no increased risk of advanced alcoholic liver disease. Gut 1998;43:262-6.

25 Ludwig J, Hashimoto E, Porayko MK, et al. Hemosiderosis in cirrhosis: a study of 447 native livers. Gastroenterology 1997;1 12:882-8.

26 Cotler SJ, Bronner MP, Press RD, et al. End-stage liver disease without hemochromatosis associated with elevated hepatic iron index. J Hepatol 1998;29:257-62

27 Turlin B, Juguet F, Moirand R, et al. Increased liver iron stores in patients with hepatocellular carcinoma developped on a non-cirrhotic liver. Hepatology 1995;22:446-50.

28 Ganne-Carrié N, Christidis C, Chastang C, et al. Liver iron is predictive of death in alcoholic cirrhosis: a multivariate study of 229 consecutive patients with alcoholic and/or hepatitis $C$ virus cirrhosis: a prospective follow up study. Gut 2000;46:277-82.
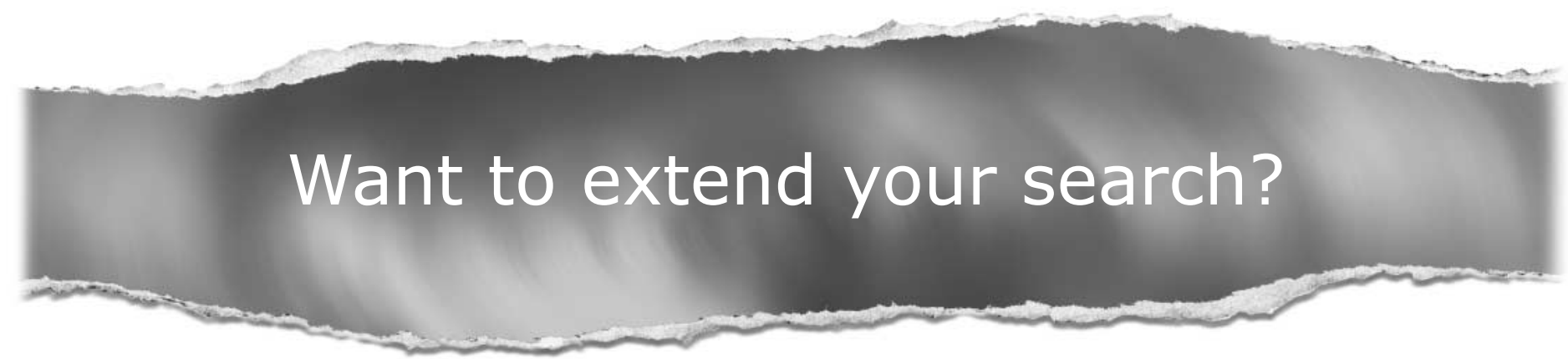

\section{Cross journal searching}

If you can't find what you are looking for in Gut you can extend your search across many of the more than 200 journals available for selection. You can restrict your search to specific subject areas (eg, clinical medicine, basic research), or select specific journals, or search all available titles.

\section{www.gutjnl.com}

